\title{
Financial Management under the Background of Electronic Commerce
}

\author{
Jian-ying Lou Wei-wei Li Qian Cui \\ Department of Economic \\ China University of Geosciences Great Wall College \\ Baoding, China
}

\begin{abstract}
The popularization and application of information technology has prompted the financial management of the enterprise to bear the impact and influence from the electronic commerce. Firstly, the connotation and characteristics of electronic commerce are analyzed. Then, combined with the actual, specific effects on enterprise financial management from electronic commerce are explored from five aspects of the environment, objectives, contents, organizational structure and business process, and the characteristics of financial management under the background of electronic commerce. Finally, specific development strategies for financial management in electronic commerce context are clarified to promote enterprises to carry out financial management work more efficiently.
\end{abstract}

Keywords: electronic commerce; financial management; characteristic; development strategy

\section{INTRODUCTION}

With the rapid development of information technology, electronic commerce has gradually become a new business operation mode with strong competitiveness in the era of network economy. Under the background of electronic commerce, enterprises are facing new opportunities and challenges, especially as a core content of enterprise management, financial management is suffering from the impact and influence from the electronic commerce. The traditional financial management can't meet the needs of the times, and the reform of financial management is imperative. Only adapting to the financial management developing requirements in the context of electronic commerce, can enterprises seize the market opportunity better in the fierce competition, developing faster, better and more stably ${ }^{[1]}$. Therefore, in the context of electronic commerce, how to improve the existing financial management has important research significance. At present, financial management researches under the background of electronic commerce focus on three aspects: one is problem that the financial management is facing under the background of electronic commerce $^{[2,3]}$, including security of financial information, limitations of financial software, demand for financial personnel, content of financial report and other aspects; two is the financial management mode under the background of elec- tronic commerce ${ }^{[4-6]}$, and new financial management modes include network financial management mode, dynamic financial management mode and online financial management mode; three is the innovation of financial management under the background of electronic commerce ${ }^{[7-9]}$, mainly concentrated on the concept innovation, model innovation, system innovation and evaluation system innovation of financial management. However, these studies have their own focuses and lack of systematicness and integrity, requiring to be further improved.

On the basis of existing financial management researches, this paper tends to define the connotation and characteristics of electronic commerce. And then combined with the actual, it will analyze the impact and influence on financial management from electronic commerce, and make the new features of financial management clear. Finally, specific development strategies and recommendations about financial management will be put forward.

\section{The connotation and characteristics of electronic commerce}

\subsection{The connotation of electronic commerce}

Electronic commerce generates and improves along with the development of information technology and network communication technology. Also, it relies on the Internet, and develops rapidly with the popularity of the Internet. Combined with the developing practice of China, the definition of electronic commerce is summed up as follow: in the global scope, it is a new business operation mode based on the open network environment of Internet in which parties to the transaction trade in goods, finance, and service and other kinds of transaction without meeting with each other. Electronic commerce can't do without two aspects: network and business. The former is the platform support of electronic commerce, the latter is the main object of electronic commerce, and both are indispensable. But electronic commerce is not equivalent to the electronization of commerce. The scope of electronic commerce is larger than that of the electronization of commerce, which includes not only the electronization of commerce, but also the full range of information control of enterprises' production, supply, marketing, service and human resources and other aspects. 


\subsection{Characteristics of electronic commerce}

Compared with the traditional business mode, electronic commerce has the following characteristic:

(1) The virtualization of transactions

Electronic commerce is a virtual trading places without fixed office space, and is not limited by time and region, realizing paperless office and the electronization of monetary. Also, its velocity of money is much faster; and because of taking the network as a platform, it can provide detailed information of goods and services for customers timely.

(2) Standardized transaction processes, streamlined and efficient

Customers can understand commodity information through website, and choose what they like with freedom. Usually, customers purchase merchandise in accordance with the procedures of the process, and there is no need for both trade sides to meet with each other, which streamlines the intermediate links, save the cost of sales, promote the cooperation and competition between enterprises, and encourage enterprises to enhance the competitiveness of products.

\section{Influences of electronic commerce on financial man- agement}

The rapid development of electronic commerce produces great influences on enterprises, especially on financial management, which is mainly reflected in five aspects of financial management environment, objectives, contents, organizational structure and business process.

\subsection{The influence of electronic commerce on financial management environment}

The rapid development of the network-based electronic commerce has brought a new economic mode, presenting the development trend of integration, diversification and sharing. The new economic mode has changed traditional patterns of work, life and consumption, such as the popularity of online shopping and online office; also it has changed the operation mode and management mode of enterprises, such as the rise of electronic commerce enterprises. The development of electronic commerce urges enterprises to pay more attention to the individual needs of consumers, take the customer as the center, attach importance to information, and depend on the innovation of scientific technology. All the above changes will affect financial management.

\subsection{The influence of electronic commerce on financial management objectives}

Scientific and reasonable financial management objective is the prerequisite for the success of enterprise's financial management. Only with a clear goal could the financial management have a clear direction. The development of electronic commerce makes the traditional goal of "benefit maximization of shareholders or enterprises" unable to adapt to requirements of the times. The rapid dissemination of information and resource sharing requires enterprises bear more social responsibility, take the sustainable development road of green business, and undertake the responsibility of environmental protection. Therefore, under the background of electronic commerce, enterprises should take the win-win between enterprises and customers as well as the long-term development of enterprises as the financial management target.

\subsection{The influence of electronic commerce on financial management contents}

The traditional financial management usually takes raw material, equipment and others as important contents, but under the background of electronic commerce, intangible assets such as talent, knowledge, technology and so on account for a marked increasing proportion of the total assets of the enterprise, playing an increasingly prominent role in the competition between enterprises. Therefore, intangible assets should be brought into financial management. In addition, due to transaction risk of electronic commerce, enterprises are faced with a crisis of confidence in the network and other business or financial risk, which requires enterprises pay attention to risk management in financial management and develop effective measures to deal with risks.

\subsection{The influence of electronic commerce on financial management organizational structure}

The organizational structure of traditional financial management is more dispersed, costing more financial and material resources, and also, larger amount of personnel are demanded larger. However, under the background of electronic commerce, various participants of financial management activities can communicate timely with each other through corresponding software, realizing the informational operations and sharing of the data. Moreover, financial management relies on the operation of information technology, as a result of which a lot of people, money and materials are saved. This transformation requires organizational structure of financial management should be made corresponding reform and adjustment according to the requirements of electronic commerce environment.

\subsection{The influence of electronic commerce on financial management business process}

The traditional financial management should follow the static business process of recording the business in accordance with records, producing recording voucher, writing into account books, forming financial statements, analyzing the statements in order to guide the enterprise management. However, under the background of electronic commerce, financial management and business process should coordinate with each other in not only convergence of all sectors within the enterprise, but also the coordination between en- 
terprise and supply chain, as well as the cooperation between enterprise and customer, which can improve work efficiency, reduce error, and achieve dynamic development and control of business process of financial management.

\section{Characteristics of financial management under the background of electronic commerce}

Under the background of electronic commerce, financial management has taken place in the larger changes from the environment to business processes, which also formed the particularity of financial management under the background of electronic commerce to a certain extent. The characteristics of financial management are embodied in two aspects: the dynamics of financial management and the synergy of financial management and enterprise business.

(1) The dynamics of financial management

The dynamics of financial management under the background of electronic commerce is embodied in three aspects as follows: 1) the dynamic collection of financial management information, that is the relevant information can be obtained through the network or authorization; 2) the dynamic recording of financial management, namely the enterprise can generate corresponding accounting information automatically and immediately after the business happening, helpful for enterprises to obtain the latest financial data, faster grasp the dynamic information of business or financial aspects, and timely make a favorable decision; 3) the dynamics of financial accounting, that is due to rely on the network, the production and business activities of enterprises show electronic characteristics, and the corresponding financial accounting has become digital activities, reflecting the activities timely and reflecting the information that can't be measured.

(2) The synergy of financial management and enterprise business

In the context of electronic commerce, financial management and enterprise business have both achieved the network operation. In the actual work, these two are interrelated and inseparable, often relying on unified information sources to make synergistic work arrangements. Moreover, the mutual synergy of financial management and enterprise business fully realizes the effective integration of information flow, capital flow and logistics, which can make enterprise information fuse as a whole, make administrators decide coordinately, and effectively avoid the decision mistakes and confusion. At the same time, this kind of synergy achieves the organic combination of multiple departments and activities, improves work efficiency, and meets the demand for human, capital and materials, much more adaptive to the market demand, which facilitates the development of enterprises under the background of electronic commerce.

\section{Development strategies of financial management un- der the background of electronic commerce}

According to influences of electronic commerce on financial management and its characteristics in new environment, the paper puts forward the following development strategies and suggestions for financial management:

(1) Establish a new concept of financial management under the background of electronic commerce

Electronic commerce is changing the development of enterprise financial management, and in order to adapt to this change, the first task is to update the concept and occupy the highlands of awareness. On the one hand, enterprises should establish the concept of competition and cooperation, properly deal with a variety of financial activities, take the interests of all parties into account, and achieve the win-win situation between enterprises. On the other hand, enterprises should always remain alert to the risks, because traditional investment risks, technology innovation risks and uncertain environmental risks all require enterprises strengthen the prevention and control of risks.

(2) Construct and improve the financial management information system under the background of electronic commerce

The development of electronic commerce makes it necessary for enterprises to establish the complete financial management information system. Firstly, the enterprise adaptability of the application platform and the related technologies should be understood. Secondly, comprehensive planning should be made, including basic platform planning, the foreground electronic commerce planning and background financial management system planning. Finally, applications should be implemented to realize the overall operation of the information system and improve the informatization level and management level of enterprises. Meantime, we should strengthen the security of information system, and proceed from two aspects of software and technology. In terms of software, we should use genuine software, and carry out legal, rational and safe inspection before using the software. In terms of technology, we should establish security and protection measures, such as the application of firewall, security protocol and encryption technology.

(3) Innovate the financial management mode under the background of electronic commerce

Financial management modes need to adapt to the requirements of electronic commerce, so it is necessary to innovate from the following four aspects: 1) referring to advanced domestic and foreign examples, and promoting the development of flat organization of financial management; 2) learning and applying advanced financial management methods such as intangible assets evaluation, comprehensive budget and so on; 3) the reform of financial management system, accounting standards and related technical standards, fully meeting the requirements of electronic commerce environment; 4) proposing a new index 
for financial evaluation, such as indexes of customer loyalty and visits number, to strengthen the expectation of financial evaluation.

\section{Conclusions}

With the gradual development and perfection of electronic commerce, its influences on financial management are becoming more and more deeply. Therefore, it is helpful to comprehensively analyze the extent of influences and new characteristics of present financial management, then put forward related countermeasures to deal with the impact of electronic commerce on financial management, and finally encourage enterprises to carry out financial management work more efficiently. In the future, the strategies and suggestions of enterprises financial management in the context of electronic commerce remain to be further improved.

\section{References}

[1] Zhang Wei, Zhang Yingna, Xie Yao. Research on Financial Management in the New Era of E-commerce Environment[J]. Manager's Journal, 2015, 12: 257.

[2] Zou Ping. The Problems and Countermeasures of Enterprise Financial Management under the Environment of E-commerce[J]. Talent Resources Development, 2014, 8:52-53.

[3] Liu Jinping. Research on Enterprise Financial Management under the Environment of E-commerce[J]. Journal of Bohai University: Philosophy and Social Science Edition, 2012 (3): 66-69.

[4] Guo Guijie. The Impact of Electronic Commerce on Financial Management Mode[J]. Industrial and Science Tribune, 2013, 11:228-229.

[5] Chen Shaoyu. Study on the Enterprise Financial Management Mode in the Electronic Commerce Environment-Taking the Small and Medium Sized Enterprises as Examples[J]. Journal of Hubei University of Economics (Humanities and Social Sciences), 2013,10 (12): $60-61$

[6] Li Yi. Analysis of Dynamic Financial Management Mode under the Background of E-commerce[J]. Modern Economic Information, 2014, 6: 169.

[7] Liu Yuhong. Research on Financial Management Innovation in Electronic Commerce Environment[J]. China Business \& Trade, 2011,20: 049.

[8] Ren Yingwei. On Finance Management Innovation under the Condition of E-Commerce[J]. Journal of Xihua University (Philosophy \& Social Sciences), 2004 (5): 44-46.

[9] Xu Jihong, Xi Ying. Countermeasures for Enterprise Financial Management in E-commerce Environment[J]. Journal of Liaoning Economic and Vocational College, 2012 (2): 25-26. 